\title{
LOW ENERGY ELECTRON CAPTURE BY MULTICHARGED IONS
}

\section{CONF-800579--1}

FROM HYDROGEN*

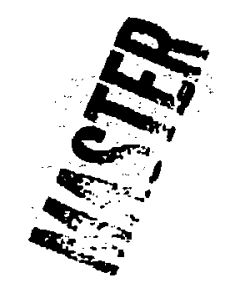

R. A. Phaneuf, D. H. Crandall, and F. W. Meyer

Oak Ridge National Laboratory, Oak Ridge, iN 37830 U.S.A.

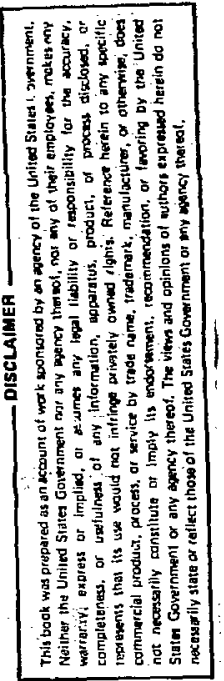

Charge exchange with hydrogen is an important recombination mechanism for tokamak impurity ions and can affect plasma parameters and the interpretation of diagnostic results. In an effort to systematicaliy investigate the behavior of low energy electron capture cross sections, we have measured cross sections for $\mathrm{Xe}^{(2-12)+}, \mathrm{Ar}^{(2-9)+}$, and $\mathrm{Fe}^{(5,6)+}$ in $\mathrm{H}$ and $\mathrm{H}_{2}$ for $3<\mathrm{E}<26 \mathrm{keV} / \mathrm{charge}$, and for $\mathrm{C}^{(3-5)+}$ in $\mathrm{H}_{2}$ for $0.15<\mathrm{E}$ $<0.45 \mathrm{keV} / \mathrm{charge}$.

Figure 1 shows the experimental electron capture cross sections for $\mathrm{Xe}^{(3-12)+}$ and $\mathrm{Ar}(3-9)+\mathrm{in}$ atomic hydrogen plotted against initial ionic charge $q$ for a fixed collision velocity. The scaling of cross sections with $q$ follows the generalized theories ${ }^{1,2}$ quite we11, but measurements are lower than predicted, and data for higher $q$ are needed to further test the theoretical scaling. In a forthcoming paper, ${ }^{3}$ additional dependences on ionic species and target electron binding energy are discussed.

Electron capture cross section data for $\mathrm{C}^{\mathrm{tq}}+\mathrm{H}_{2}$ col1isions $(q=3,4,5)$ have been obtained at much lower impact energies using a laser-produced plasma as an ion source and a time-of-f1ight technique. Figure 2 compares these data to data obtained at higher energies using other sources of multicharged ions. ${ }^{4,5}$ It is significant that $c^{4+}$ has the 1 argest cross section at the very lowest velocities, counter-indicating a simple scaling with ionic charge. The cross sections for charges 3,4 , and 5 also a11 increase with decreasing velocity in this region. Measurements will be extended to $\mathrm{O}^{+q}$ and $\mathrm{Fe}^{+q}$ ions and to an atomic hydrogen target to provide a direct comparison with emerging models of low energy charge exchange. ${ }^{6}$

*Research sponsored by the Office of Fusion Energy of the U.S. Department of Energy, under contract W-7405-eng-26 with the Union Carbide Corporation. 
1. T. P. Grodzanov and R. K. Janev, Phys. Rev. A 17 (1978) 880.

2. R. E. 01 son and A. Salop, Phys. Rev. A 14 (1976) 579.

3. D. H. Crandal1, R. A. Phaneuf, and F. W. Meyer. (Submitted to Phys. Rev. A).

4. D. H. Crandall, R. A. Phaneuf, and F. W. Meyer, Phys. Rev. A 19 (1979) 504.

5. R. A. Phaneuf, F. W. Meyer, and R. H. Mcknight, Phys. Rev. A 17 (1978) 534.

6. R. E. 01son, "Electron Capture Between Multiply-Charged Ions and One Electron Targets," in Electronic and Atomic Collisions, ed. N. Oda and K. Takayanagi (North KolTand, 1980) pp 391-405.

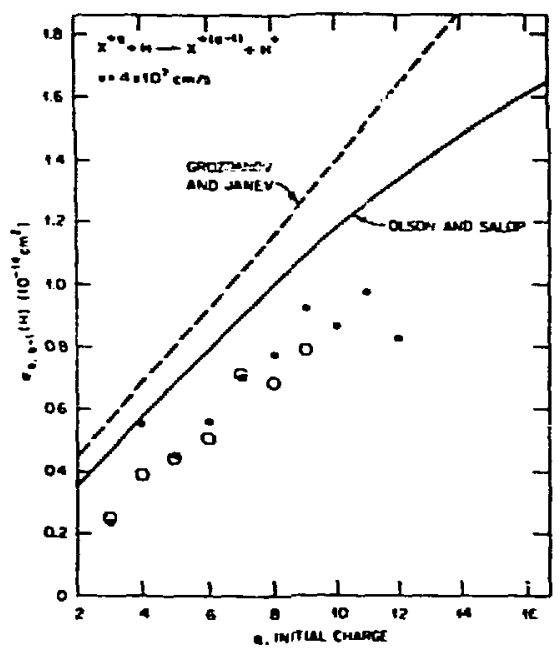

'Fig. 1 Electron capture cross sections vs ionic charge $q$ for $X e^{+q}$ (open circles) and Arta (solid circles) in atomic hydrogen at fixed velocity. Scalings predicted by generalized theories are shown for comparison.

Fig. 2 Electron capture cross sections vs ion velocity for $\mathrm{C}^{+\mathrm{q}}+\mathrm{H}_{2}$ collisions. Numbers on graph denote 9 . Circled points are taken from Ref. 5 ; numbers wi thout flags from Ref. 4. Numbers with flags are unpublished data using laser ion source.

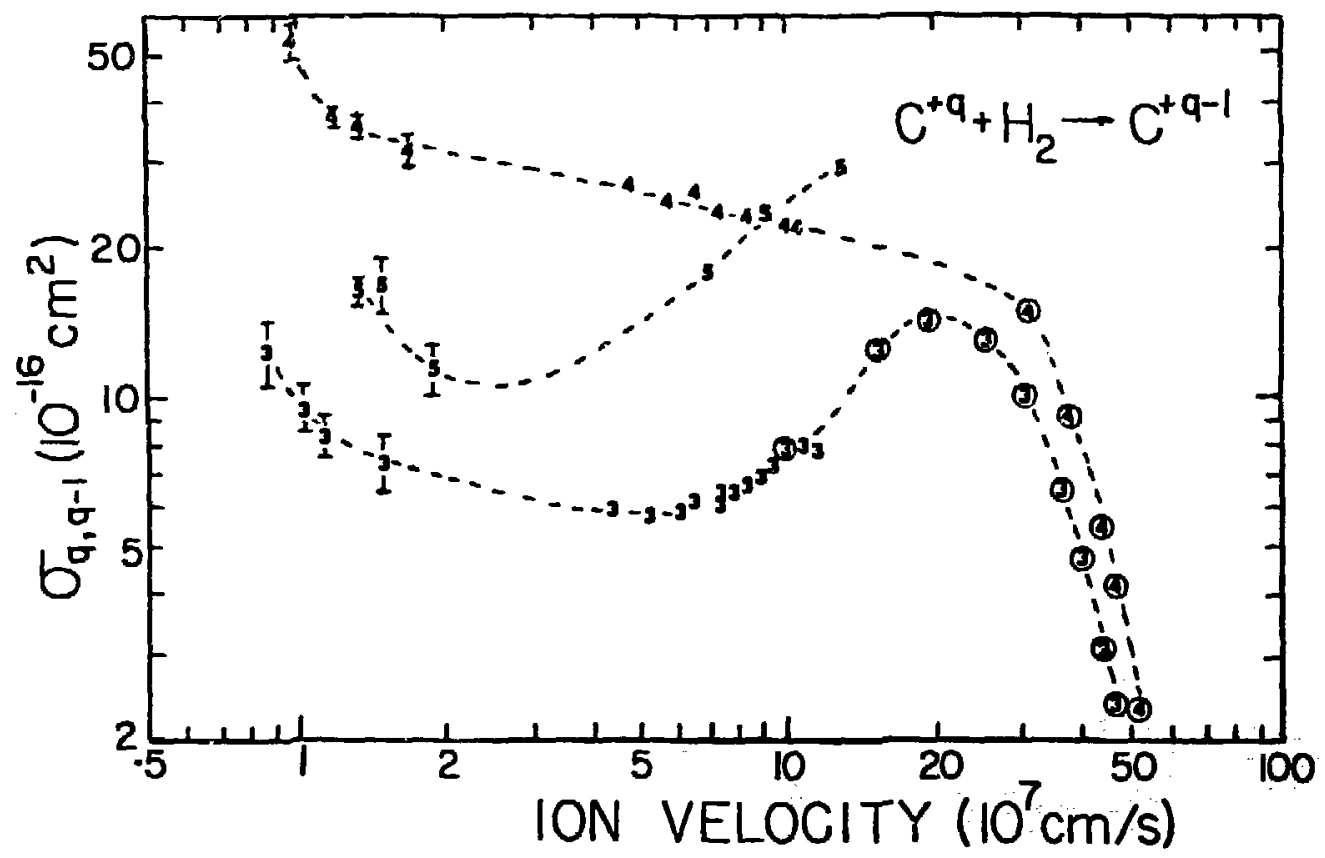

